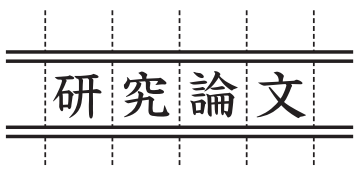

\title{
Formation of Ni-base Self-fusing Layers with Using Direct Diode Laser
}

\author{
Junji MORIMOTO*, Taisuke OZAKI*, Toshifumi KOBAYASI*, \\ Takayoshi KUSUHARA*, Nobuyuki ABE** and Masahiro TSUKAMOTO**
}

(Received August 31, 2009)

\begin{abstract}
The Ni-base self-fusing alloy layers are employed in a variety of wear resistance applications. The diode laser is more compact and the electro-optical-efficiency is higher about one order of magnitude. This is an advantage in both the small-size manufacturing field and large-size construction out door field. Another advantage is the wavelength. Due to shorter wave length most of the metals absorb diode laser $(808 \mathrm{~nm})$ radiation more efficiently compared with $\mathrm{CO}_{2}$ laser $(10600 \mathrm{~nm})$ enabling together with high power the use of wide beam optics. In this paper, five types of laser cladding conditions (laser power, scan speed, overlap rate, powder injection position and laser irradiation position) are examined and the structures and mechanical properties of the layers produced by each cladding condition are discussed. The Vickers hardness of laser cladding Ni-base S.F. alloy layer was increased from HV740 to 845 with increase in the layer power from $150 \mathrm{~W}$ to $250 \mathrm{~W}$. Some recommended laser cladding processing conditions for a Ni-base S.F. alloy powder were scan speed of $6 \mathrm{~mm} / \mathrm{sec}$, overlap rate of $60 \%$, powder feeder nozzle angle of $60^{\circ}$ and laser power of $200 \mathrm{~W}$.
\end{abstract}

Key Words: Direct Diode Laser, Ni-base Self-fusing Alloy, Wear Resistant, Vickers Hardness, Laser Cladding

\section{INTRODUCTION}

Laser cladding is an economic process to produce protective layers against wear and corrosion on highly loaded components ${ }^{1)}$. Advantages of laser cladding are uses of high melting point materials, low heat influence and heat distortion to a substrate, and high adhesion strength of a cladding layer. Laser cladding is expected as a surface modification technology to apply against the materials which are required in severe environments. The Ni-base self-fluxing alloy thermal sprayed coatings are widely employed to improve the quality of components whose surface is submitted to wear and corrosion. The use of thermal spray coatings for the wear protection of bulk materials is used throughout industry for mechanical components such as engine parts, hydraulic turbines and bearing surfaces ${ }^{2,3)}$.

For the past few years, the authors have been developing a laser cladding method employing a high energy density laser beam heat source ${ }^{4,5)}$. Utilizing this method, steel plate was coated with Fe-B alloy powder to produce a hard surfacing layer with high hardness and erosion resistance ${ }^{6}$. To develop a more effective cladding process, laser cladding was investigated using a powder feeder and Ni base self-fluxing alloy powder. The deposition efficiency and the thermal efficiency in dependence on the processing speed are determined. With minimal overall heat input, functional layers with thickness of millimeters are obtained and the surface processed per time unit is increased. Powder feed rate and track offset have to be adjusted simultaneously in order to obtain a sufficient cladding quality. The laser cladding layers were examined by optical microscope, scanning electron microscope and electron probe micro analyzer. The properties of the cladding layer were examined using the Vickers hardness test and sand erosion test.

\section{EXPERIMENTAL PROCEDURES}

\subsection{Materials}

Rotating tube-shaped samples of stainless steel with an outer diameter of $42.7 \mathrm{~mm}$, an inner diameter of $36.7 \mathrm{~mm}$ and a length of $500 \mathrm{~mm}$ were used for the experiments. Prior to laser cladding, the substrate was degreased in $\mathrm{Al}_{2} \mathrm{O}_{3}$ grit blasted, cleansed in alcohol and dried by a high pressure air jet. The particle size of Nibase self-fluxing alloy powder was limited within $25 \mu \mathrm{m}-32 \mu \mathrm{m}$ to ensure uniform melting by the laser beam, as shown in Fig.1. Chemical composition of Ni-base self-fluxing alloy powder is shown in Table1.

\subsection{Laser cladding method}

A photograph of the experimental apparatus is shown in Fig.2. This diode laser system consists of very small diode laser head, a power supply and a water cooling unit. The size of the laser head was $100 \mathrm{~mm} \times 85 \mathrm{~mm} \times 290 \mathrm{~mm}$ and weighted $5.5 \mathrm{~kg}$. A maximum output power was $443 \mathrm{~W}$ and a wavelength was 808

\footnotetext{
*Faculty of Science and Technology, Kinki University (Kowakae, Higashi-Osaka, Osaka 577-8502, Japan)

***oining and Welding Research Institute, Osaka University (11-1 Mihogaoka, Ibaraki, Osaka 567-0047, Japan)
} 


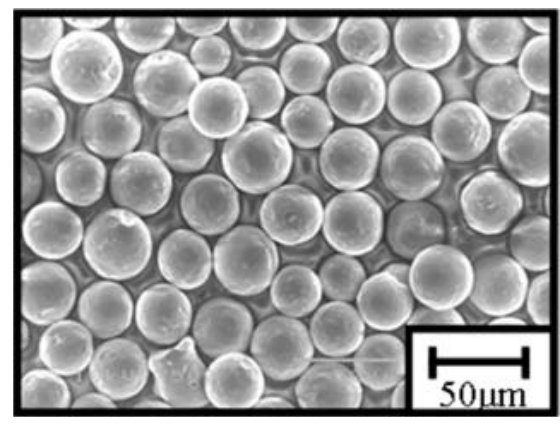

Fig.1 SEM image of Ni-base self-fluxing alloy powder.

Table1 Composition of Ni-base self-fluxing alloy powder.

\begin{tabular}{|c|c|c|c|c|c|}
\hline $\mathrm{Cr}$ & $\mathrm{Si}$ & $\mathrm{B}$ & $\mathrm{Fe}$ & $\mathrm{C}$ & $\mathrm{Ni}$ \\
\hline $16.0 \sim 18.0$ & $3.9 \sim 4.9$ & $3.2 \sim 3.5$ & $3.0 \sim 5.0$ & $0.8 \sim 1.0$ & Bal. \\
\hline
\end{tabular}

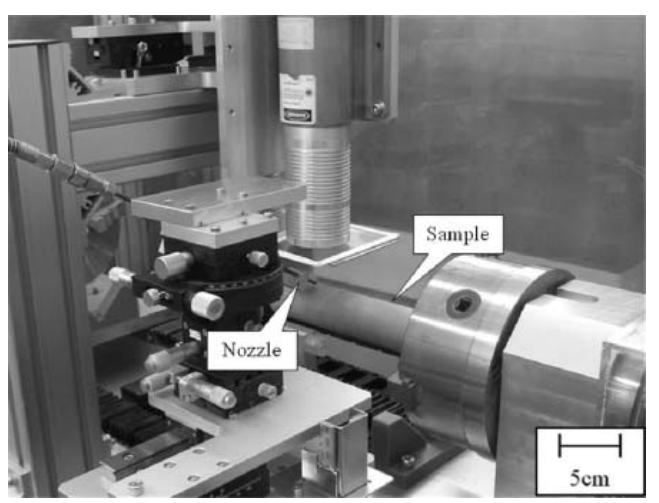

Fig.2 $500 \mathrm{~W}$ class direct diode laser system.

$\mathrm{nm}$. The beam profile was examined by using a UFF100 beam profiler. The focal point was $42.5 \mathrm{~mm}$ length. The laser beam size was $230 \mu \mathrm{m}-1820 \mu \mathrm{m}$.

A powder injection position and a laser irradiation position are shown in Fig.3. Laser irradiation is carried out on the position of L1 $\left(90^{\circ}\right)$, L2 $\left(60^{\circ}\right)$, L3 $\left(45^{\circ}\right)$ and L4 $\left(30^{\circ}\right)$ of stainless steel pipe surface. A powder feeder nozzle with an inner diameter of $2.0 \mathrm{~mm}$ was used in order to cover the expected melt pool caused by the laser beam. The powder particles are moving by a nitrogen gas. The powder feed rate was varied from $2.35 \mathrm{~g} / \mathrm{min}$ to $7.48 \mathrm{mg} / \mathrm{min}$. By rotating the sample continuously and moving the laser beam with a constant velocity over the substrate, single layers were deposited as continuous spiral onto the cylindrical sample. For this study, the scan speed was varied in the range of $3 \mathrm{~mm} / \mathrm{sec}$ to $30 \mathrm{~mm} / \mathrm{sec}$. Depending on the scan velocity the overlap rate was changed. Subsequently, the sample was sectioned, mounted and polished for microscopic examination and Vickers hardness test-
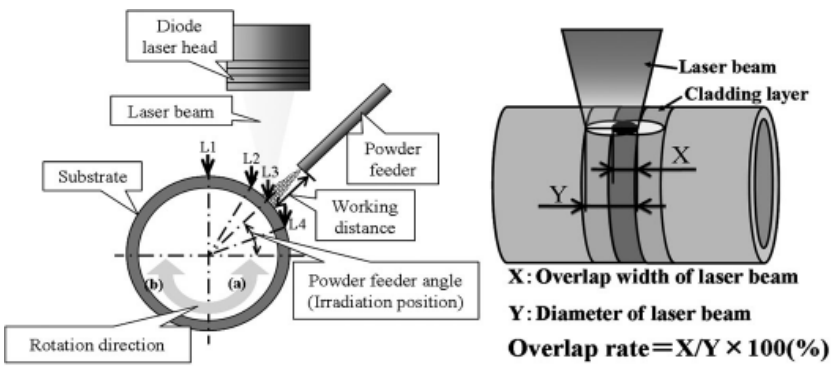

Fig.3 Laser cladding of a pipe with HPDL.

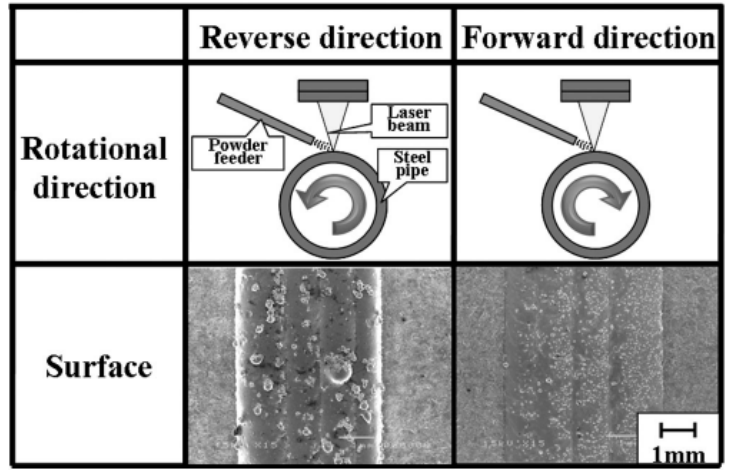

Fig.4 Surface morphologies of Ni-base S.F alloy layer at different rotation direction.

ing. The specimens were then etched in a 3\% Nital solution and were examined in the optical microscope. The Vickers hardness tester is applied to get the hardness of cladding layer. Both the top surfaces and the transverse sections of specimens were examined under a SEM to identify the process defects including cracks. The wear resistance of cladding layer was evaluated using blast erosion test. The pressure of the compressed air was $0.35 \mathrm{MPa}$. The impact angle during test was fixed at $90^{\circ}$. Steel grit with a nominal size of $350 \mu \mathrm{m}$ was employed as the erodent. Specimens were cleaned with acetone and weighed to an accuracy of $0.1 \mathrm{mg}$ on an electronic balance before and after the test to determine weight loss. Surface roughness of cladding layer was determined by using a laser scanning microscope.

\section{RESULT AND DISCUSSION}

In general the cladding layer was influenced by the overlap rate, the powder feed rate, the laser power and the scan velocity. The relationship between surface of layer and rotation direction for the Ni-S.F. base alloy layer is shown in Fig.4. It was noticed that powder feed manner, i.e. using injection of rotation direction or injection of rotation opposite direction. Surface of Ni-base S.F alloy layers in Fig.4 results for the rotation direction indicated in Fig.3. Surface roughness was also influenced by rotation direc- 


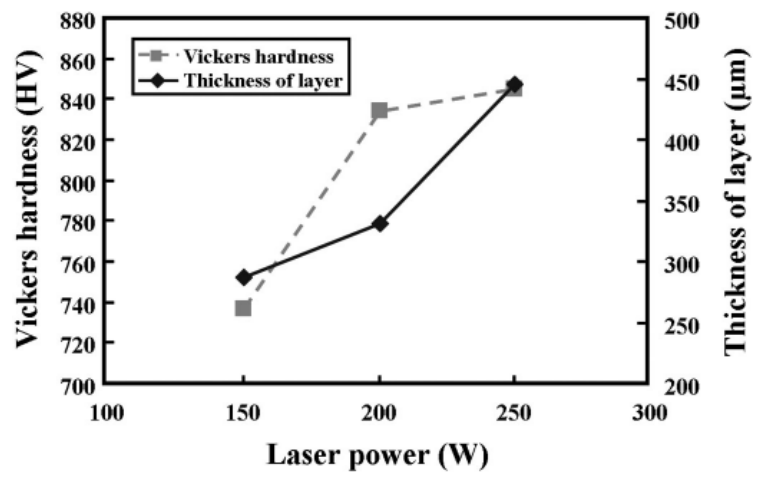

Fig.5 Vickers hardness and thickness of cladding layer of the Ni-base S.F. alloy layer in various laser power.

\begin{tabular}{|c|c|c|c|}
\hline Scan speed & $4 \mathrm{~mm} / \mathrm{sec}$ & $6 \mathrm{~mm} / \mathrm{sec}$ & $8 \mathrm{~mm} / \mathrm{sec}$ \\
\hline Surface & & & \\
\hline & & & \\
$\begin{array}{c}\text { Cross } \\
\text { section }\end{array}$ & & & \\
\hline $\begin{array}{c}\text { Vichers hardness } \\
\text { (Hv) }\end{array}$ & 876 & 834 & 837 \\
\hline $\begin{array}{c}\text { chichness of } \\
\text { chadding hayer(m) }\end{array}$ & 565 & 331 & 251 \\
\hline
\end{tabular}

Fig.6 Surface appearances, cross section and Vickers hardness results of Ni-base S.F. alloy layer. (Power $200 \mathrm{~W}$ )

tion, a smooth layer was achieved at same direction against pipe rotation. In the case of opposite direction against pipe rotation, deposition efficiency was increased, but the unevenness surface was increased, and the defect part was recognized. The condition of same direction against pipe rotation gives the best structure and surface roughness.

Figure 5 shows the relation between the average Vickers hardness of layer and the laser power at scan speed of $6 \mathrm{~mm} / \mathrm{sec}$. The Vickers hardness measurements were taken perpendicular to the polished surface of the cladding layer.

The Vickers hardness of cladding Ni-base S.F. alloy layers was increased from HV740 to HV845 with increase on the laser power from $150 \mathrm{~W}$ to $250 \mathrm{~W}$. The deposition efficiency of cladding Nibase S.F. alloy layers was increased with increasing laser power. The surface roughness as cladding layers decreased at laser power of $250 \mathrm{~W}$. This means that the low porosity leads to higher hardness of cladding layer.

Figure 6 shows the measured average Vickers hardness and thickness of layer for the three different scan speed.

The deposition efficiency of cladding Ni-base S.F. alloy layers was increased with decreasing scan speed of laser beam. At diode

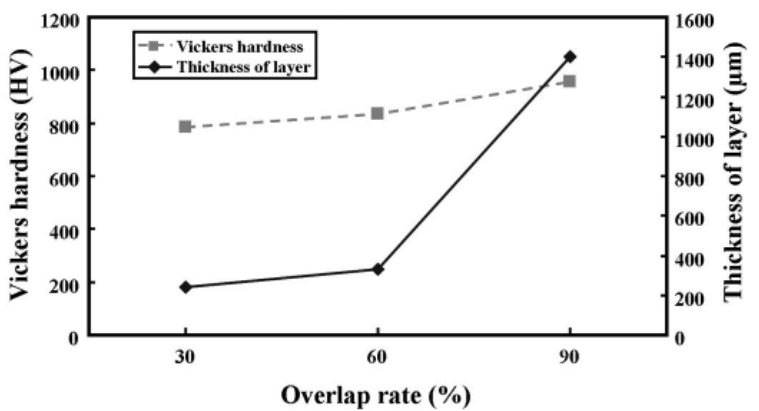

Fig.7 Vickers hardness and Thickness of cladding Ni-base S.F. alloy layer as a function of overlap rate. (Power $200 \mathrm{~W}$, Scan speed $6 \mathrm{~mm} / \mathrm{sec}$ )

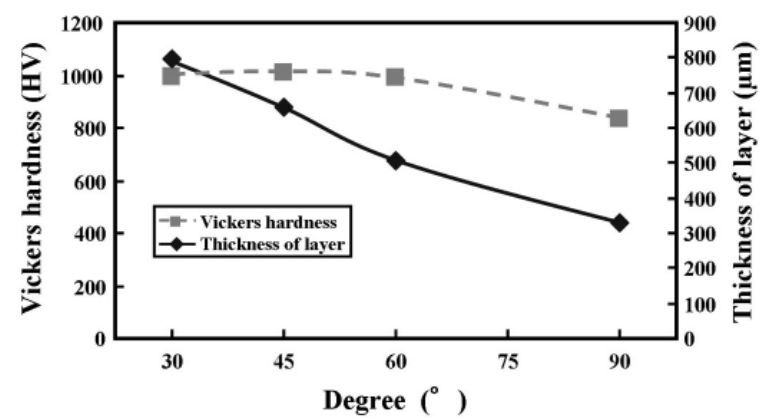

Fig.8 Vickers hardness and Deposition efficiency Ni-base with powder feeder angles. (Overlap rate 50\%, Laser power 200 W, Scan speed 6 $\mathrm{mm} / \mathrm{sec}$ )

laser parameter of $200 \mathrm{~W}$ and $4 \mathrm{~mm} / \mathrm{sec}$, small cracks were observed in the cross section. Form the surface morphology demonstrated in Fig.6, it is found that the Ni-base S.F. alloy particles are totally melted during laser radiation. At the scan speed of $6 \mathrm{~mm} /$ sec, the structure of layer had dense and few cracks and pores.

The effect of the overlap rate on the Vickers hardness and deposition efficiency was shown in Fig.7. The thickness of Ni-base S.F. alloy layer is about 7 times higher when the overlap rate increased from $30 \%$ to $90 \%$. However the unevenness surface of layer was increased and the defect part was recognized. On the other hand, the Vickers hardness increased with increase of overlap rate.

The Vickers hardness and deposition efficiency in Fig.8 resulted for the four powder feeder nozzle angles of L1, L2, L3 and L4 indicated in Fig.3. The deposition efficiency strongly depended on powder feeder angle. A maximum deposition efficiency was obtained at the powder feeder angle of $30^{\circ}$. At the powder feeder angle of $45^{\circ}$, the Ni-base S.F. alloy layer of more than $650 \mu \mathrm{m}$ in thickness were formed. The cladding layer / substrate interface is uniform compared with that of thermal spraying process. The highest hardness value (HV1012) was measured for a powder feeder angle of $45^{\circ}$ while the lowest hardness value (HV834) was a powder feeder angle of $90^{\circ}$. This may be attributed to the melt- 


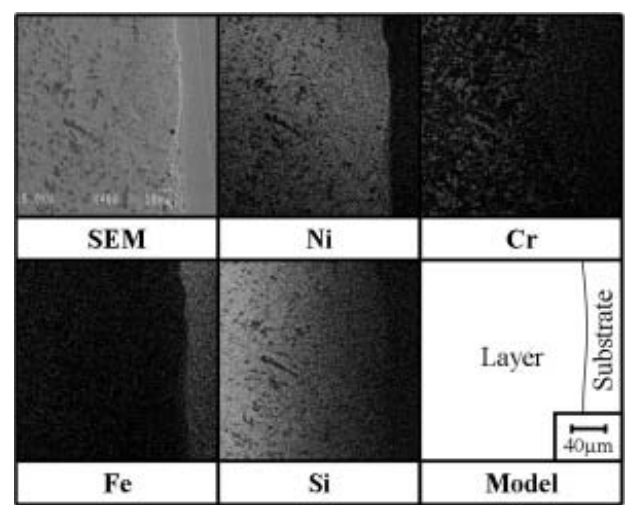

Fig.9 SEM photograph and X-ray images of cross section of cladding Nibase S.F. alloy layer produced at $200 \mathrm{~W}$ for $6 \mathrm{~mm} / \mathrm{sec}$

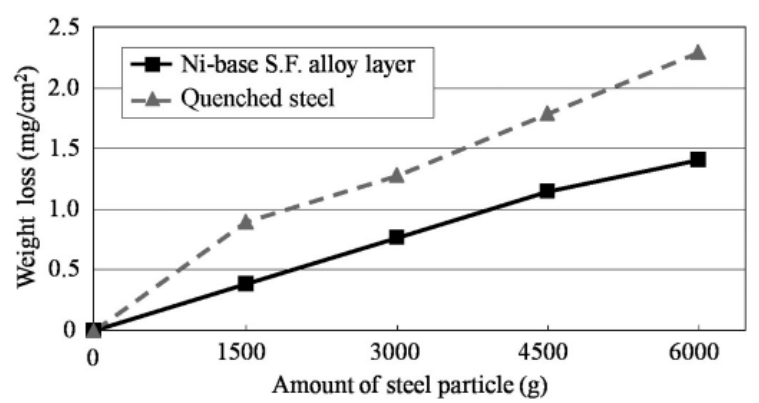

Fig.10 Results of blast erosion test with laser cladding Ni-base S.F. alloy layer produced at $200 \mathrm{~W}$ for $6 \mathrm{~mm} / \mathrm{sec}$

ing time of particles was increased with decreasing angle of laser irradiation position.

The EPMA images of Ni-base S.F. alloy layer treated at a laser power of $200 \mathrm{~W}$ and scan speed of $6 \mathrm{~mm} / \mathrm{sec}$ was shown in Fig.9. It was observed that the $\mathrm{Ni}, \mathrm{Cr}$ and $\mathrm{Si}$ were distributed uniformly. It is clearly seen that the substrate material did not mix with the cladding layer.

The weight loss values measured during the sand erosion test on laser cladding Ni-base S.F. alloy layers and the water quenched steels are depicted in Fig.10. Compared to the cladding layer, the quenched steel of HV 736 hardness was used for the blast erosion test. The relationship between the weight loss and the amount of steel particles as the erodent was proportional for both the cladding layer and quenched steel. At the blast erosion test with the steel grit of $6000 \mathrm{~g}$, the weight loss of the quenched steel was 2.38 $\mathrm{g}$, and the weight loss of cladding layer decreased to $1.46 \mathrm{~g}$. The erosion wear resistant of cladding Ni-base S.F. alloy layers was better than the quenched steel.

\section{CONCLUSIONS}

This paper reports the results of the laser cladding for stainless steel pipe.

(1) The Vickers hardness of cladding Ni-base S.F. alloy layer was increased from HV740 to HV845 with increase in the layer power from $\mathrm{p}=150 \mathrm{~W}$ to $250 \mathrm{~W}$.

(2) The deposition efficiency of cladding Ni-base S.F. alloy layer strongly depended on the powder feeder angle. A maximum deposition efficiency was obtained at the powder feeder angle of $30^{\circ}$. At the powder feeder nozzle angle of $45^{\circ}$, the Ni-base self-fusing alloy layers of more than $650 \mu \mathrm{m}$ in thickness were formed.

(3) Some recommended laser cladding processing conditions for a Ni-base S.F. alloy powder are scan speed of $6 \mathrm{~mm} / \mathrm{sec}$, overlap rate of $60 \%$, powder feeder angle of $60^{\circ}$ and laser power of 200 W.

(4) The erosion wear resistant of laser cladding Ni-base S.F. alloy layer was better than the quenched steel.

\section{REFERENCES}

1) G.Habedank, C.Theiler, M.Grupp, H.Kokn, and F.Vollertsen, ”Laser beam cladding of steel with High Power Diode Lasers” Proceeding of the second International WLT-conference on lasers in Manufacturing. 46-49(2003).

2) K.A.Khor, L.G.Yu and G.Sundararajan, "Formation of hard tungsten boride layer by spark plasma sintering boriding”, Thin Solid Films, 478, p.232-237 (2005).

3) J.Morimoto, and N.Abe. "Surface Modification of Sprayed Coating and Forming Hard Layer by Direct Diode Laser”, (in Japanese) J.High Temp. Soc., 34-6, 287-292 (2007).

4) A.Morikawa, N.Abe, M.Tsukamoto J.Morimoto, and S.Noguchi, "Formation of Hard Surfacing Layers with Diode Lasers" Proceeding of the second International WLT-conference on lasers in Manufacturing. 57-60(2003)

5) J.Morimoto, N.Abe, M.Tsukamoto and Y.Katoh, "Surface Modification of Thermal Sprayed Coating by Direct Diode Laser”, J.High Temp. Soc., 34-6, 293-296 (2008).

6) J.Morimoto, N.Abe, M.Tsukamoto and Y.Katoh, "Boronizing of Steel with Diode Laser Cladding”, Proceeding of the $14^{\text {th }}$ Annual Meeting of IAPS, (in Japanese) 137 (2008). 